\title{
Taguchi Grey Relational Optimization of the Multi- mechanical Characteristics of Kaolin Reinforced Hydroxyapatite: Effect of Fabrication Parameters
}

\author{
Johnson Kehinde Abifarin ${ }^{1, *} \mid$ David Olubiyi Obada ${ }^{1} \mid$ \\ Emmanuel Toi Dauda ${ }^{2}$ | Elijah Oyewusi Oyedeji ${ }^{3}$ \\ ${ }^{1}$ Department of Mechanical Engineering, Ahmadu Bello University, Zaria, Nigeria \\ ${ }^{2}$ Department of Metallurgical and Materials Engineering, Ahmadu Bello University, Zaria, Nigeria \\ ${ }^{3}$ National Space Research and Development Agency (NASRDA), Abuja, Nigeria \\ *Corresponding author: jkabifarin@abu.edu.ng
}

Received 5 August 2021; Revised 9 September 2021; Accepted 10 September 2021

\begin{abstract}
Comparative study of kaolin reinforced hydroxyapatite (KHAp) and pure HAp using different production parameters has been done through traditional experimentation. However, the quantitative effect, optimization of kaolin reinforcement and fabrication parameters have not been investigated. Hence, this study examines the effect of kaolin reinforcement, compaction pressure and sintering temperature on the experimental mechanical properties of HAp. Taguchi design assisted by grey relational analysis was employed with L36 (2**2 $3 * * 1)$ orthogonal array. The Minitab 16 software was used to analyze the Taguchi design. The result showed a disparity in kaolin reinforcement as the optimum condition for individual mechanical properties, but the grey relational analysis showed better mechanical properties with kaolin reinforcement, 500 $\mathrm{Pa}$ compaction pressure and $1100{ }^{\circ} \mathrm{C}$ sintering temperature. The obtained result further revealed kaolin reinforcement as a strong and promising reinforcing material for high strength clinical application, having a contribution of $93.16 \%$ on compressive strength of HAp. Therefore, future studies can be conducted in the use of different $w t \%$ of kaolin on the multi-response mechanical characteristics of HAp.
\end{abstract}

Keywords: Grey relational analysis; optimization; hydroxyapatite; kaolin; production parameters; mechanical properties

\section{Introduction}

Hydroxyapatite (HAp) with the chemical formula of Ca10(PO4)6(OH)2 is a calcium phosphate based bio-ceramic because it forms a mechanically strong bond to bone and typically no fibrous particles are found inherent on the implants' surface. These attractive properties make HAp a good material in clinical applications such as bio-medical implants and substitutes for the repair of damaged bones (Caliman et al., 2017; Adeogun et al., 2018). The constant use of HAp is due to its unique chemical composition, in addition to its biological and crystallographic similarity with the 
mineral portion of hard tissues, for instance, bones and teeth. HAp has received attention as a good candidate for biomedical application, due to its excellent biocompatibility and high rate of cell proliferation. Because of its poor mechanical strength, extensive research has been geared towards the improvement of HAp mechanical properties. The use of foreign material as a reinforcing agent has been reported in the literature (Santos et al., 1994; Lahiri et al., 2012; Zhao et al., 2018; Singh et al., 2020; Singh et al., 2021). Reinforcement is an action or process of reinforcing or strengthening a weak material.

Taguchi design of the experiment is a method of mitigating laboratory robustness and also a way of optimizing design parameters or process parameters of singular response of a product or system. The design was named after the Japanese quality guru Genichi Taguchi who invented it (Taguchi \& Phadke, 1989; Taguchi, 1993; Taguchi et al., 2005). While Grey Relational Analysis (GRA) is employed when there is a need to optimize design parameters for multiple response characteristics. It is also used when a process or design is uncertain or complicated (Julong, 1989; Javed, 2019). This study employed Taguchi design assisted by the GRA to mitigate the indecision on the best combination of fabrication parameters for better mechanical integrity of HAp. Taguchi-grey relational analysis has been usedare as follows: Sylajakumari et al. (2018) optimized production parameters on the multi-wear responses of a co-continuous composite with the help of Taguchigrey relational analysis. Bademlioglu et al. (2020) employed Taguchi grey relational analysis to investigate and to optimize the working parameters affecting the multiple performance characteristics of an organic Rankine cycles. Almetwally (2020) carried out multi-objective optimization of woven fabric parameters using Taguchi-grey relational analysis.

In light of the synthesis and mechanical improvement of hydroxyapatite, Abifarin et al. (2019) synthesized and characterized pure HAp for biomedical application. The mechanical properties of the synthesized HAp were further worked upon by Obada et al. (2020) and Obada et al. (2021) using $15 \mathrm{wt} \%$ kaolin and different sintering parameters. Recently, Abifarin (2021) employed Taguchi grey relational analysis to determine and to optimize quantitatively the effect of sintering parameters on pure HAp. Kaolin was employed as a reinforcement in the bulk HAp because it is a silica based materials with excellent biocompatibility (Obada et al., 2021). The reinforcement of HAp with kaolin in this study is referred to as kaolin reinforced HAp. Having reported traditional experimentation of $15 \mathrm{wt} \%$ kaolin reinforcement and the effect of compaction pressure and sintering temperature on the mechanical properties of HAp, it is expedient to examine the quantitative effect and the optimization of fabrication parameters of kaolin reinforced HAp. Hence, this study employed Taguchi grey relational analysis as the statistical tool to investigate the optimum production parameters and its quantitative effect on the mechanical properties of HAp. Table 1 describes the employed based materials and its fabrication parameters.

Table 1. Definitions of base materials and fabrication parameters

\begin{tabular}{|l|l|l|}
\hline \multicolumn{1}{|c|}{ Variable } & \multicolumn{1}{|c|}{ Definition } & \multicolumn{1}{c|}{ Reference } \\
\hline Hydroxyapatite & $\begin{array}{l}\text { Hydroxyapatite is a calcium phosphate based ceramic, } \\
\text { having chemical formula of } \mathrm{Ca}_{10}\left(\mathrm{PO}_{4}\right)_{6}(\mathrm{OH})_{2}\end{array}$ & $\begin{array}{l}\text { Posner } \text { et al. (1958); } \\
\text { Orlovskii } \text { et al. } \text { (2002) }\end{array}$ \\
\hline Kaolin & $\begin{array}{l}\text { Kaolin is a silica based material with a chemical } \\
\text { formula of } \mathrm{Al}_{2} \mathrm{O}_{3} 2 \mathrm{SiO}_{2}\end{array}$ & $\begin{array}{l}\text { Murray (1980); Chen } \text { et al. } \\
(1997) ; \text { Schroeder and } \\
\text { Erickson (2014) }\end{array}$ \\
\hline Reinforcement & $\begin{array}{l}\text { Reinforcement is an action or process of reinforcing } \\
\text { or strengthening a weaker material. }\end{array}$ & $\begin{array}{l}\text { Seward (1956); Byrne and } \\
\text { Clore (1970) }\end{array}$ \\
\hline $\begin{array}{l}\text { Kaolin reinforced } \\
\text { hydroxyapatite }\end{array}$ & $\begin{array}{l}\text { Kaolin reinforced hydroxyapatite is a composite } \\
\text { showing hydroxyapatite as the main matrix, } \\
\text { strengthened by kaolin }\end{array}$ & The present work \\
\hline $\begin{array}{l}\text { Sintering } \\
\text { temperature }\end{array}$ & $\begin{array}{l}\text { It is the annealing temperature at which material } \\
\text { mechanical and microstructural properties are } \\
\text { improved }\end{array}$ & $\begin{array}{l}\text { Kuang } \text { et al. (1997); } \\
\text { Abifarin (2021) }\end{array}$ \\
\hline $\begin{array}{l}\text { Compaction } \\
\text { pressure }\end{array}$ & $\begin{array}{l}\text { It is the pressure at which a material scaffold is } \\
\text { formed or made }\end{array}$ & $\begin{array}{l}\text { German (2010); Abifarin } \\
\text { (2021) }\end{array}$ \\
\hline
\end{tabular}




\section{Materials and Method}

HAp/KHAp synthesis, characterization and mechanical properties evaluation have been reported in the previous study (Obada et al., 2021). This study employed statistical Taguchi grey relational analysis to examine the quantitative effect of kaolin reinforcement and production parameters (compaction pressure and sintering temperature) on the reported experimental hardness and compressive strength. Figure 1 shows the overall experimental procedure on how the mechanical properties were obtained in the study of Obada et al. (2021).

\subsection{Taguchi experimental design}

The factors and their respective levels were employed based on the design consideration based on the previous study (Obada et al., 2021), and was formulated using Taguchi design strategy as shown in Table 2 . The suitable orthogonal array employed according to Minitab 16 software was L36 $(2 * * 23 * * 1)$, and it is displayed in Table 3. The corresponding experimental hardness, compressive strength and resultant grey relational grade were analyzed using Taguchi on Minitab. The steps for generating the resultant grey relational grade for the experimental mechanical properties are shown in section 2.2, and are similar to the work of Abifarin (2021) and Awodi et al. (2021). All the plotted graphs were obtained using Minitab. Figure 2 shows the overview of Taguchi-grey relational optimization analysis.

\subsection{Grey relational analysis}

Integration of GRA into the Taguchi method can improve the performance of Taguchi method for optimization (Chang et al., 2000). As it is impossible to directly average experimental hardness and compressive strength, grey relational analysis was employed to address the impossibility (Julong, 1989; Javed et al., 2019). First, hardness and compressive strength values were converted to grey relational generation (normalizing the sequence) using the larger-the-better consideration as shown in Equation 1. The larger-the-better was employed because high hardness and compressive strength is desired. After sequence normalization, deviation sequence of the reference sequence was computed using Equation 2. Next, grey relational coefficient was generated using Equation 3, and thereafter the resultant hardness and compressive strength grey relational coefficients were average to have grey relational grade (GRG) using Equation 4.

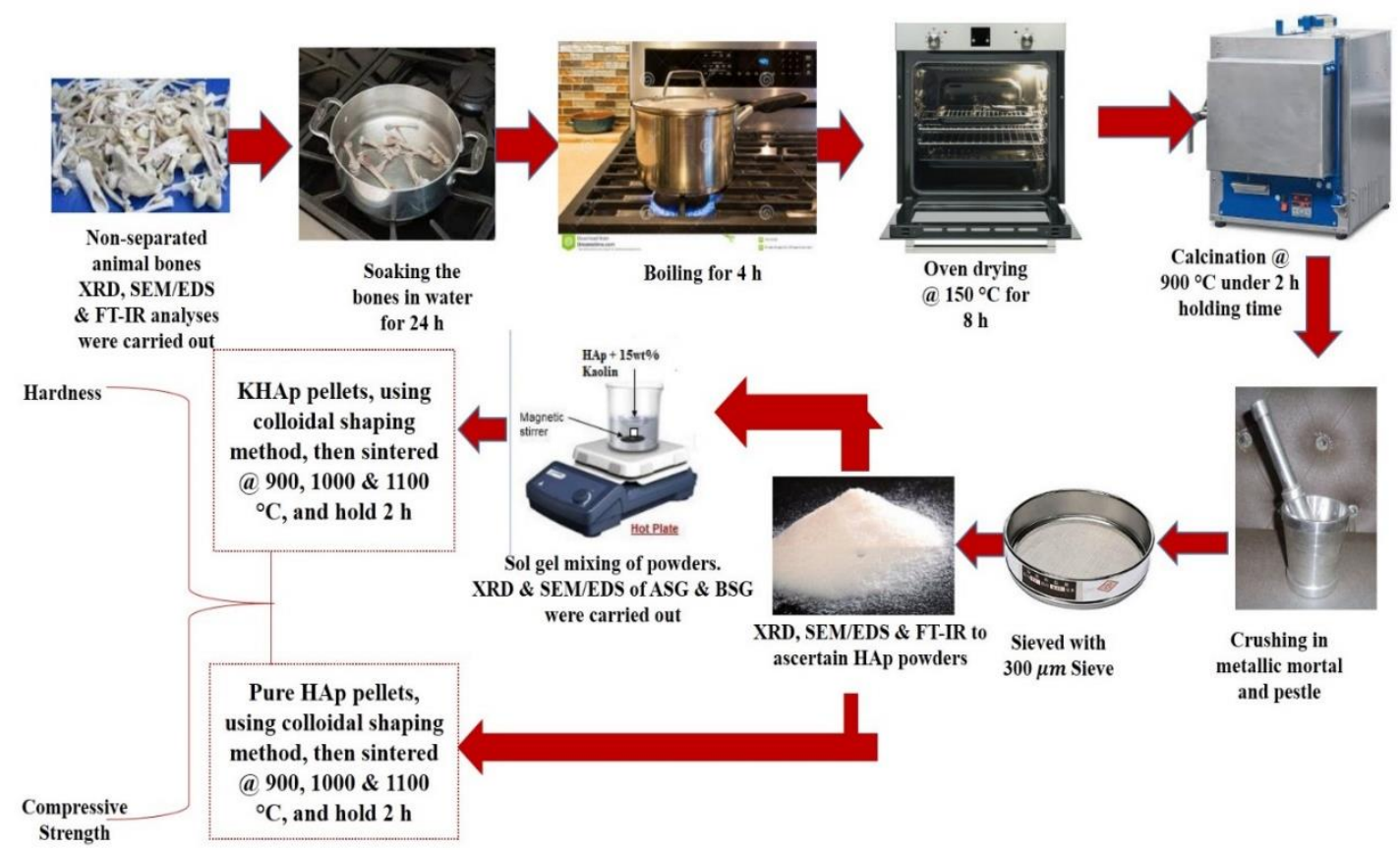

Figure 1. Mechanical synthesis of pure and kaolin reinforced hydroxyapatite 


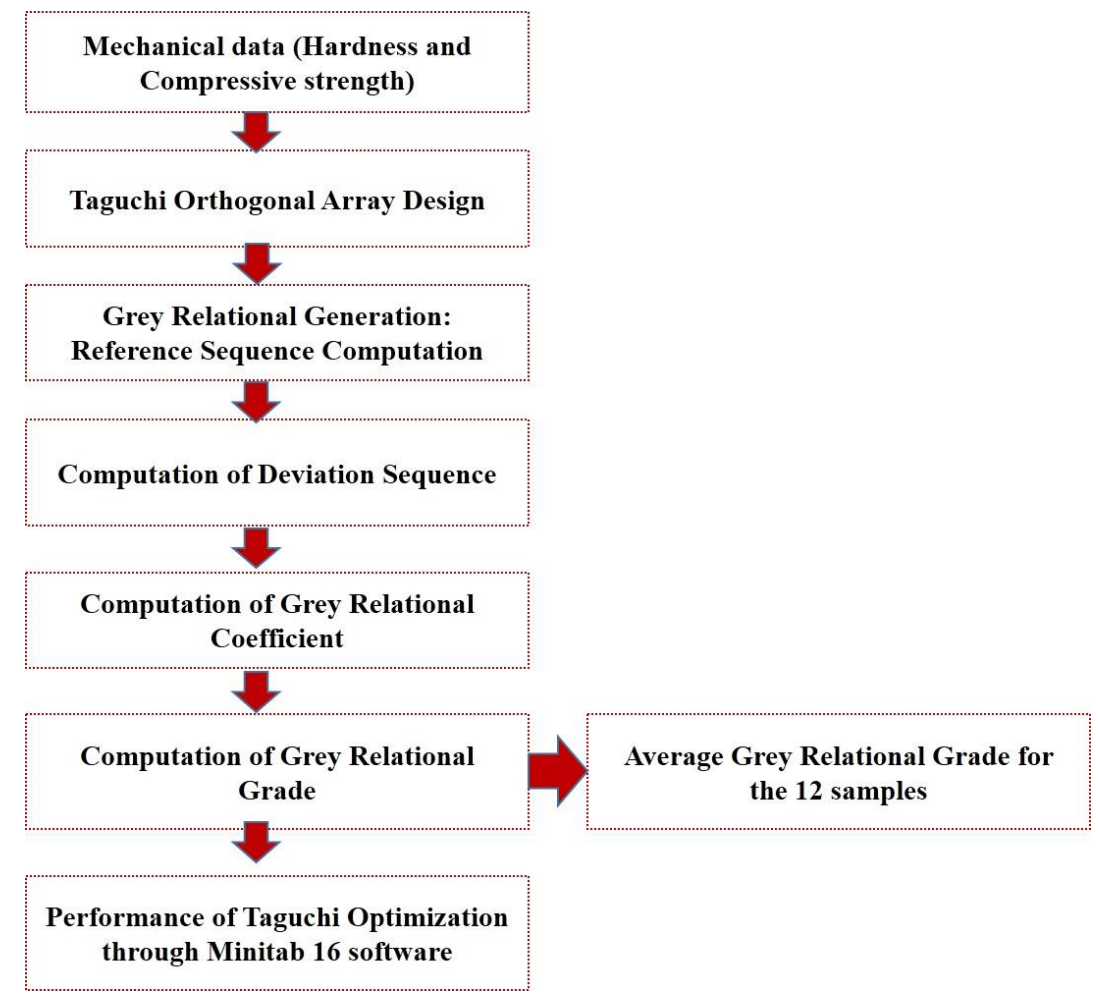

Figure 2. Taguchi-grey relational optimization analysis

$$
x_{i}(k)=\frac{y_{i}(k)-\min y_{i}(k)}{\max y_{i}(k)-\min y_{i}(k)}
$$

Note that $x_{i}(k)$ is the normalized data for the $i^{t h}$ experiment, and $y_{i}(k)$ denotes the initial sequence of the mean of the responses

$$
\Delta_{0 i}(k)=\left|x_{0}(k)-x_{i}(k)\right|
$$

Here, $\Delta_{0 i}(k), x_{0}(k)$, and $x_{i}(k)$ are the deviation, reference and comparability sequences respectively.

$$
\xi_{i}(k)=\frac{\Delta_{\min }+\zeta \Delta_{\max }}{\Delta_{0 i}(k)+\zeta \Delta_{\max }}, \zeta \in(0,1)
$$

where $\xi_{i}(k)$ symbolizes GRC of individual response variables calculated as a function of $\Delta_{\min }$ and $\Delta_{\text {max }}$, the minimum and maximum deviations of each response variable. $\zeta$ is the distinguishing coefficient (Mahmoudi et al., 2020) whose value was considered 0.5 in the current study.

$$
\gamma_{i}=\frac{1}{n} \sum_{i=1}^{n} \xi_{i}(k)
$$

where $\gamma_{i}$ is the GRG determined for the $i^{\text {th }}$ experiment, $n$ is the aggregate count of the performance characteristics. Since the Taguchi orthogonal array design displayed three replications for the experimental run, the average grey relational grade (AGRG) for each treatment (sample) was computed afterwards.

Table 2. Factors and their levels

\begin{tabular}{|c|c|c|c|}
\hline Fabrication parameter & $\mathbf{W t} \mathbf{t}$ kaolin & Compaction pressure(Pa) & Sintering temperature $\left({ }^{\circ} \mathbf{C}\right)$ \\
\hline Level 1 & 0 & 0 & 900 \\
\hline Level 2 & 15 & 500 & 1000 \\
\hline Level 3 & - & - & 1100 \\
\hline
\end{tabular}


Table 3. Taguchi experimental design strategy

\begin{tabular}{|c|c|c|c|}
\hline Experimental no. & $\mathrm{Wt} \%$ kaolin & Compaction pressure $(\mathbf{P a})$ & Sintering temperature $\left({ }^{\circ} \mathbf{C}\right)$ \\
\hline 1 & 0 & 0 & 900 \\
\hline 2 & 0 & 0 & 1000 \\
\hline 3 & 0 & 0 & 1100 \\
\hline 4 & 0 & 0 & 900 \\
\hline 5 & 0 & 0 & 1000 \\
\hline 6 & 0 & 0 & 1100 \\
\hline 7 & 0 & 0 & 900 \\
\hline 8 & 0 & 0 & 1000 \\
\hline 9 & 0 & 0 & 1100 \\
\hline 10 & 0 & 500 & 900 \\
\hline 11 & 0 & 500 & 1000 \\
\hline 12 & 0 & 500 & 1100 \\
\hline 13 & 0 & 500 & 900 \\
\hline 14 & 0 & 500 & 1000 \\
\hline 15 & 0 & 500 & 1100 \\
\hline 16 & 0 & 500 & 900 \\
\hline 17 & 0 & 500 & 1000 \\
\hline 18 & 0 & 500 & 1100 \\
\hline 19 & 15 & 0 & 900 \\
\hline 20 & 15 & 0 & 1000 \\
\hline 21 & 15 & 0 & 1100 \\
\hline 22 & 15 & 0 & 900 \\
\hline 23 & 15 & 0 & 1000 \\
\hline 24 & 15 & 0 & 1100 \\
\hline 25 & 15 & 0 & 900 \\
\hline 26 & 15 & 0 & 1000 \\
\hline 27 & 15 & 0 & 1100 \\
\hline 28 & 15 & 500 & 900 \\
\hline 29 & 15 & 500 & 1000 \\
\hline 30 & 15 & 500 & 1100 \\
\hline 31 & 15 & 500 & 900 \\
\hline 32 & 15 & 500 & 1000 \\
\hline 33 & 15 & 500 & 1100 \\
\hline 34 & 15 & 500 & 900 \\
\hline 35 & 15 & 500 & 1000 \\
\hline 36 & 15 & 500 & 1100 \\
\hline
\end{tabular}

\section{Results and discussion}

\subsection{Effect of kaolin and production parameters on hardness}

Figure 3 shows effect of kaolin, compaction pressure and sintering temperature on HAp hardness value. The result revealed that $15 \mathrm{wt} \%$ of kaolin dropped HAp hardness value, but 500 $\mathrm{Pa}$ compaction pressure had a little increasing effect on the hardness value. However, increase in sintering temperature had a significant increasing effect on HAp hardness value. Hence, the optimal factors levels for better hardness are HAp without kaolin reinforcement, $500 \mathrm{~Pa}$ compaction pressure and $1100{ }^{\circ} \mathrm{C}$ sintering temperature.

\subsection{Quantitative effect of reinforcement and production parameters on $H A p$ bardness}

Statistical ANOVA data of the Taguchi result is highlighted in Table 4. As effect of the considered factors has been discussed in section 3.1, it is important to have their quantitative effect which is displayed in Table 3. The result revealed that when kaolin reinforcement was not employed, there was a significant contribution of $46.04 \%$. The sintering temperature factor shows the most significant contribution of $50.76 \%$ on HAp hardness value. Even though, $500 \mathrm{~Pa}$ 


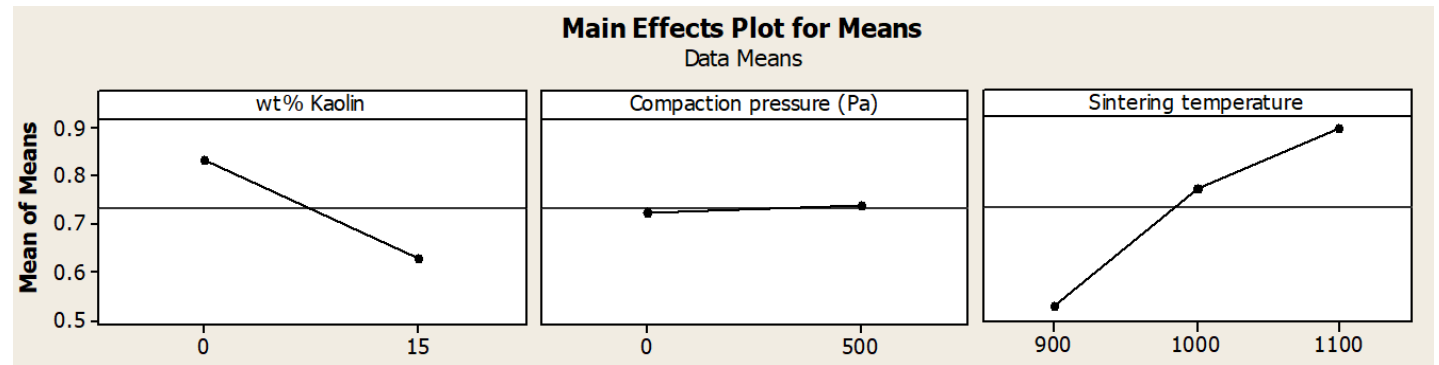

Figure 3. Effect of factors on hardness

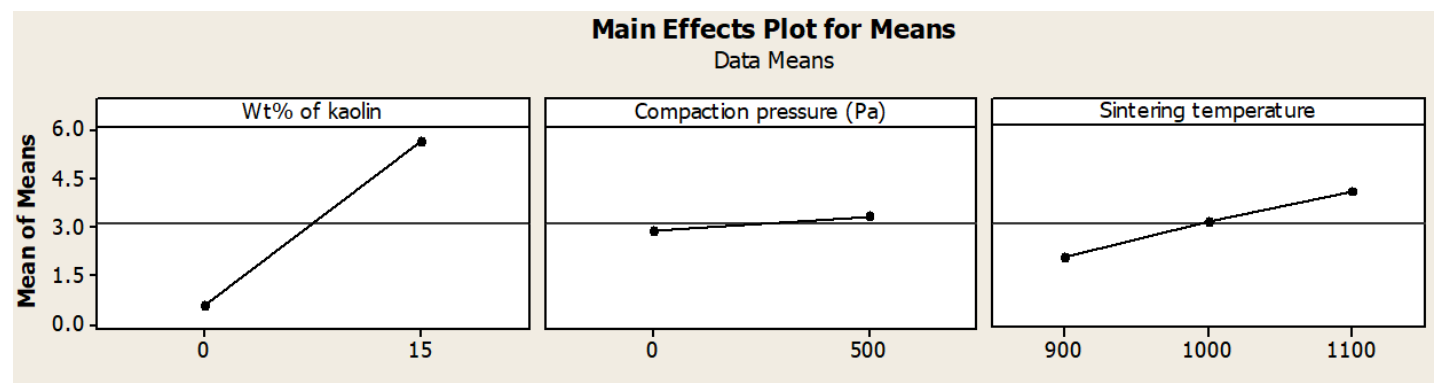

Figure 4. Effect of factors on compressive strength

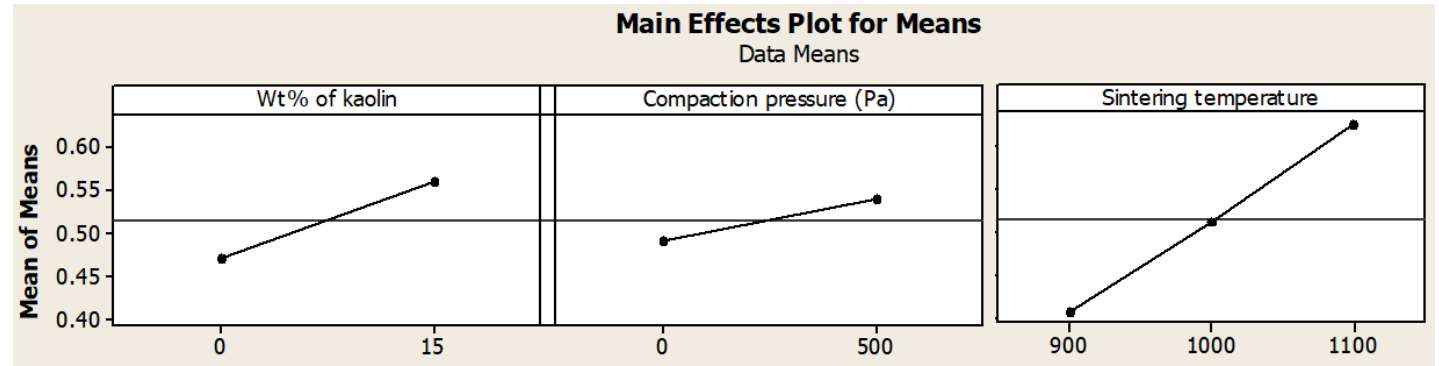

Figure 5. Effect of factors on grey relational grade

compaction pressure had a little increasing effect, its contribution $(0.24 \%)$ and the contribution of residual error $(2.96 \%)$ on HAp hardness are insignificant.

\subsection{Effect of kaolin and production parameters on compressive strength}

It is important to note from the compressive strength result revealed in Figure 4 was significantly increased with inclusion of kaolin. The reason for the increment has been discussed in the previous study (Obada et al., 2021). Equally, this result showed that the two production parameters considered in this study had an increasing effect on the compressive strength of HAp. Meaning, the optimal factors are $15 \mathrm{wt} \%$ of kaolin reinforcement, $500 \mathrm{~Pa}$ compaction pressure and $1100{ }^{\circ} \mathrm{C}$ sintering temperature.

Table 4. ANOVA for HAp hardness value

\begin{tabular}{|l|c|c|c|c|c|c|}
\hline $\begin{array}{c}\text { Fabrication } \\
\text { parameter }\end{array}$ & DOF & Adj SS & Adj MS & F & $\begin{array}{c}\text { Contribution } \\
\mathbf{\%}\end{array}$ & Remark \\
\hline Wt $\%$ of kaolin & 1 & 0.128133 & 0.128133 & 15.54 & 46.04 & Significant \\
\hline $\begin{array}{l}\text { Compaction } \\
\text { pressure }\end{array}$ & 1 & 0.000655 & 0.000655 & 0.08 & 0.24 & Insignificant \\
\hline $\begin{array}{l}\text { Sintering } \\
\text { temperature }\end{array}$ & 2 & 0.282524 & 0.141262 & 17.13 & 50.76 & Significant \\
\hline Residual error & 7 & 0.057720 & 0.008246 & & 2.96 & Insignificant \\
\hline Total & 11 & & 0.278296 & $\mathrm{~S}=0.09081$ & $\mathrm{R}^{2}=87.7 \%$ & $\mathrm{R}^{2}$ Adj $^{2} 80.7 \%$ \\
\hline
\end{tabular}




\subsection{Quantitative effect of reinforcement and production parameters on HAp compressive strength}

The quantitative effect of addition of kaolin and production parameters are shown in Table 5 . Interestingly, other factors did not have much significance on HAp compressive strength except kaolin reinforcement having contribution of $93.16 \%$. Meaning, without the consideration of the production parameters, kaolin reinforcement has a robust increasing effect on the compressive strength of HAp.

\subsection{Grey relational evaluation}

It is essential to optimize input processing parameters of HAp for its multiple mechanical properties. Grey relational analysis gives conclusive input parameters for high strength HAp. Table 6 and Table 7 highlight the analysis of grey relational grade, while Figure 5 and Table 5 show the effect of kaolin reinforcement, compaction pressure and sintering temperature on the multiresponse grey relational grade. It is important to note that, for the multi-response mechanical properties, kaolin reinforcement had an increasing effect on the mechanical properties. Also, compaction pressure, $500 \mathrm{~Pa}$ shows a higher increasing effect compared with the individual hardness and compressive strength properties. As the sintering temperature increased, the multiresponse mechanical properties increased as it is on individual hardness and compressive strength. Hence, it can be conclusively said that, kaolin reinforcement had a positive impact on the overall mechanical properties of HAp, and the optimal conditions for high strength of HAp are $15 \mathrm{wt} \%$ kaolin reinforcement, $500 \mathrm{~Pa}$ compaction pressure and $1100{ }^{\circ} \mathrm{C}$ sintering temperature.

Table 7 and Figure 6 show the grey relational grade (GRG) result. The graph in Figure 6 displays experimental number 30,33, and 36 as the highest GRG, which is also depicted in Table 8. Since the experimental numbers displaying the highest GRG, it was then average to have the mean value of GRG, which gave 0.7445 as the experimental optimum GRG value.

Table 5. ANOVA for HAp Compressive strength

\begin{tabular}{|l|c|c|c|c|c|c|}
\hline Fabrication parameters & DOF & Adj SS & Adj MS & F & Contribution \% & Remark \\
\hline Wt $\%$ of kaolin & 1 & 77.335 & 77.335 & 85.92 & 93.16 & Significant \\
\hline Compaction pressure & 1 & 0.6832 & 0.6832 & 0.76 & 0.82 & Insignificant \\
\hline Sintering temperature & 2 & 8.1961 & 4.0980 & 4.55 & 4.94 & Insignificant \\
\hline Residual error & 7 & 6.3007 & 0.9001 & & 1.08 & Insignificant \\
\hline Total & 11 & & 83.016 & $\mathrm{~S}=0.949$ & $\mathrm{R}^{2}=93.2 \%$ & $\mathrm{R}^{2} \mathrm{Adj}^{=}=89.3 \%$ \\
\hline
\end{tabular}

Table 6. Response mean for GRG

\begin{tabular}{|c|c|c|c|}
\hline Level & $\mathbf{W t} \mathbf{\%}$ of kaolin & Compaction pressure & Sintering temperature \\
\hline 1 & 0.4704 & 0.4911 & 0.4075 \\
\hline 2 & 0.5585 & 0.5378 & 0.5111 \\
\hline 3 & - & - & 0.6248 \\
\hline Delta & 0.0882 & 0.0467 & 0.2173 \\
\hline Rank & 2 & 3 & 1 \\
\hline Note: Total mean of GRG: 0.515 & \multicolumn{2}{l}{} \\
\hline
\end{tabular}

\subsection{Quantitative effect of reinforcement and production parameters on $H A p$ GRG}

As the qualitative effect has been revealed above, Table 9 reveals the quantitative effect of the controlling factors on GRG values. The result revealed sintering temperature as the most significant production factor having a contribution of $60.21 \%$, followed by kaolin reinforcement with a contribution of $29.72 \%$, and compaction pressure with a contribution of $8.32 \%$. Importantly, the result revealed that the residual error was insignificant on the HAp GRG. 


\subsection{Confirmation analysis}

3.7.1 Confidence interval analysis: After determining the optimal fabrication parameters, its predicted grey relational grade was computed as 0.6911 using Table 5 and Equation 5 (Ross, 1996; Abifarin, 2021; Abifarin et al., 2021).

$$
\gamma_{\text {predicted }}=\gamma_{m}+\sum_{i=1}^{q} \gamma_{0}-\gamma_{m}
$$

$\gamma_{0}$ highlights the highest GRG response under each fabrication parameter, while $\gamma_{m}$ is the total average GRG value. $q$ is the number of fabrication parameters.

To investigate the authenticity of the predicted response and experimental response, confidence interval (CI) was calculated using Equation 6 (Taguchi \& Phadke, 1989; Abifarin, 2021; Awodi et al., 2021):

Table 7. Reference and deviation sequence after pre-processing of data

\begin{tabular}{|c|c|c|c|c|}
\hline \multirow[t]{2}{*}{ Experiment run } & \multicolumn{2}{|c|}{ Reference Sequence $x_{i}^{*}$} & \multicolumn{2}{|c|}{ Deviation Sequence $\Delta_{0 i}$} \\
\hline & HV & CS & $\mathrm{HV}$ & CS \\
\hline 1 & 0.269663 & 0.00515 & 0.73034 & 0.99485 \\
\hline 2 & 0.603371 & 0.03995 & 0.39663 & 0.96005 \\
\hline 3 & 0.730337 & 0.06443 & 0.26966 & 0.93557 \\
\hline 4 & 0.247191 & 0.01418 & 0.75281 & 0.98582 \\
\hline 5 & 0.775281 & 0.02706 & 0.22472 & 0.97294 \\
\hline 6 & 0.689888 & 0.06959 & 0.31011 & 0.93041 \\
\hline 7 & 0.325843 & 0.01933 & 0.67416 & 0.98067 \\
\hline 8 & 0.469663 & 0.0451 & 0.53034 & 0.9549 \\
\hline 9 & 0.77191 & 0.07861 & 0.22809 & 0.92139 \\
\hline 10 & 0.424719 & 0 & 0.57528 & 1 \\
\hline 11 & 0.755056 & 0.02062 & 0.24494 & 0.97938 \\
\hline 12 & 1 & 0.05284 & 0 & 0.94716 \\
\hline 13 & 0.451685 & 0.01418 & 0.54831 & 0.98582 \\
\hline 14 & 0.746067 & 0.03995 & 0.25393 & 0.96005 \\
\hline 15 & 0.88764 & 0.0451 & 0.11236 & 0.9549 \\
\hline 16 & 0.358427 & 0.00515 & 0.64157 & 0.99485 \\
\hline 17 & 0.651685 & 0.02062 & 0.34831 & 0.97938 \\
\hline 18 & 0.853933 & 0.0567 & 0.14607 & 0.9433 \\
\hline 19 & 0.258427 & 0.37887 & 0.74157 & 0.62113 \\
\hline 20 & 0.541573 & 0.5683 & 0.45843 & 0.4317 \\
\hline 21 & 0.396629 & 0.82603 & 0.60337 & 0.17397 \\
\hline 22 & 0.348315 & 0.38144 & 0.65169 & 0.61856 \\
\hline 23 & 0.477528 & 0.67139 & 0.52247 & 0.32861 \\
\hline 24 & 0.5 & 0.9317 & 0.5 & 0.0683 \\
\hline 25 & 0.255056 & 0.34536 & 0.74494 & 0.65464 \\
\hline 26 & 0.460674 & 0.65851 & 0.53933 & 0.34149 \\
\hline 27 & 0.651685 & 0.82861 & 0.34831 & 0.17139 \\
\hline 28 & 0.105618 & 0.54768 & 0.89438 & 0.45232 \\
\hline 29 & 0.364045 & 0.86856 & 0.63596 & 0.13144 \\
\hline 30 & 0.606742 & 0.9317 & 0.39326 & 0.0683 \\
\hline 31 & 0 & 0.47552 & 1 & 0.52448 \\
\hline 32 & 0.320225 & 0.71005 & 0.67978 & 0.28995 \\
\hline 33 & 0.503371 & 0.9884 & 0.49663 & 0.0116 \\
\hline 34 & 0.149438 & 0.55799 & 0.85056 & 0.44201 \\
\hline 35 & 0.304494 & 0.72552 & 0.69551 & 0.27448 \\
\hline 36 & 0.588764 & 1 & 0.41124 & 0 \\
\hline
\end{tabular}




$$
C I=\sqrt{F_{\alpha}\left(1, f_{e}\right) V_{e}\left[\frac{1}{\eta_{e f f}}+\frac{1}{R}\right]}
$$

$F_{\alpha}\left(1, f_{e}\right)$ is the required $\mathrm{F}$ ratio for risk, $\alpha ; f_{e}$ is the degree of freedom (DOF) of error; $V_{e}$ is variance of error; $\eta_{\text {eff }}$ is effective number of replications. If $R$ represents the number of experimental repetitions when the investigation is done for affirmation and $N$ represents all the experiments carried out then $\eta_{e f f}$ is given by:

$$
\eta_{\text {eff }}=\frac{N}{1+(\text { total DOF of control factors })}
$$

Therefore, if $V_{e}=0.001372 ; f_{e}=7$; DOF of all the control factors is 4 ; $R$ is $1 ; N$ is $36 ; \alpha=0.5$ under $95 \%$ confidence interval $(\mathrm{CI})$, then $F_{0.5}(1,7)=5.59$ based on the F-statistical table. Consequently, $\eta_{\text {eff }}=\frac{36}{1+4}=7.2$ and $C I=\sqrt{5.59 \times 0.001372\left[\frac{1}{7.2}+\frac{1}{1}\right]}= \pm 0.0935 .95 \%$ of confidence interval for the optimal grey relational grade predicted is given in Equation 8 (Abifarin,

\begin{tabular}{|c|c|c|c|}
\hline \multirow[t]{2}{*}{ Experiment run } & \multicolumn{2}{|c|}{ Grey relational coefficient, $\varepsilon_{i}(k)$} & \multirow[t]{2}{*}{ GRG $\gamma_{i}$} \\
\hline & $\mathrm{HV}$ & CS & \\
\hline 1 & 0.40639 & 0.33448 & 0.37044 \\
\hline 2 & 0.55764 & 0.34245 & 0.45005 \\
\hline 3 & 0.64964 & 0.34829 & 0.49896 \\
\hline 4 & 0.3991 & 0.33651 & 0.36781 \\
\hline 5 & 0.68992 & 0.33946 & 0.51469 \\
\hline 6 & 0.6172 & 0.34955 & 0.48337 \\
\hline 7 & 0.42584 & 0.33768 & 0.38176 \\
\hline 8 & 0.48528 & 0.34367 & 0.41447 \\
\hline 9 & 0.68673 & 0.35177 & 0.51925 \\
\hline 10 & 0.46499 & 0.33333 & 0.39916 \\
\hline 11 & 0.67119 & 0.33798 & 0.50459 \\
\hline 12 & 1 & 0.3455 & 0.67275 \\
\hline 13 & 0.47696 & 0.33651 & 0.40673 \\
\hline 14 & 0.66319 & 0.34245 & 0.50282 \\
\hline 15 & 0.81651 & 0.34367 & 0.58009 \\
\hline 16 & 0.43799 & 0.33448 & 0.38624 \\
\hline 17 & 0.5894 & 0.33798 & 0.46369 \\
\hline 18 & 0.77391 & 0.34643 & 0.56017 \\
\hline 19 & 0.40271 & 0.44598 & 0.42435 \\
\hline 20 & 0.52169 & 0.53665 & 0.52917 \\
\hline 21 & 0.45316 & 0.74187 & 0.59752 \\
\hline 22 & 0.43415 & 0.447 & 0.44058 \\
\hline 23 & 0.48901 & 0.60342 & 0.54622 \\
\hline 24 & 0.5 & 0.87982 & 0.68991 \\
\hline 25 & 0.40162 & 0.43304 & 0.41733 \\
\hline 26 & 0.48108 & 0.59418 & 0.53763 \\
\hline 27 & 0.5894 & 0.74472 & 0.66706 \\
\hline 28 & 0.35858 & 0.52503 & 0.44181 \\
\hline 29 & 0.44016 & 0.79184 & 0.616 \\
\hline 30 & 0.55975 & 0.87982 & 0.71978 \\
\hline 31 & 0.33333 & 0.48805 & 0.41069 \\
\hline 32 & 0.42381 & 0.63295 & 0.52838 \\
\hline 33 & 0.50169 & 0.97733 & 0.73951 \\
\hline 34 & 0.37022 & 0.53078 & 0.4505 \\
\hline 35 & 0.41823 & 0.64559 & 0.53191 \\
\hline 36 & 0.54871 & 1 & 0.77435 \\
\hline
\end{tabular}
2021),

Table 8. Rank of grey relational coefficient (GRC) and grey relational grade (GRG) 
Table 9. Grey relational grade (GRG), and average grey relational grade (AGRG)

\begin{tabular}{|c|c|c|c|c|c|c|c|}
\hline Sample & Experiment run & GRG & AGRG & Sample & Experiment run & GRG & AGRG \\
\hline \multirow{3}{*}{ 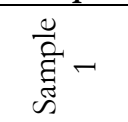 } & 1 & 0.370 & \multirow{3}{*}{0.373} & \multirow{3}{*}{ 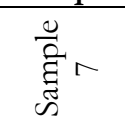 } & 19 & 0.424 & \multirow{3}{*}{0.427} \\
\hline & 4 & 0.368 & & & 22 & 0.441 & \\
\hline & 7 & 0.382 & & & 25 & 0.417 & \\
\hline \multirow{3}{*}{ 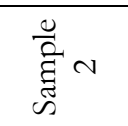 } & 2 & 0.450 & \multirow{3}{*}{0.460} & \multirow{3}{*}{ 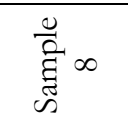 } & 20 & 0.529 & \multirow{3}{*}{0.538} \\
\hline & 5 & 0.515 & & & 23 & 0.546 & \\
\hline & 8 & 0.414 & & & 26 & 0.538 & \\
\hline \multirow{3}{*}{ 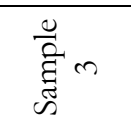 } & 3 & 0.499 & \multirow{3}{*}{0.501} & \multirow{3}{*}{ 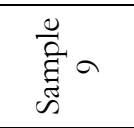 } & 21 & 0.598 & \multirow{3}{*}{0.652} \\
\hline & 6 & 0.483 & & & 24 & 0.690 & \\
\hline & 9 & 0.519 & & & 27 & 0.667 & \\
\hline \multirow{3}{*}{ 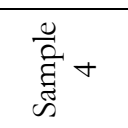 } & 10 & 0.399 & \multirow{3}{*}{0.397} & \multirow{3}{*}{ 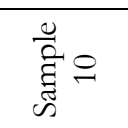 } & 28 & 0.442 & \multirow{3}{*}{0.434} \\
\hline & 13 & 0.407 & & & 31 & 0.411 & \\
\hline & 16 & 0.386 & & & 34 & 0.451 & \\
\hline \multirow{3}{*}{ 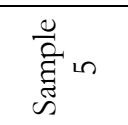 } & 11 & 0.505 & \multirow{3}{*}{0.490} & \multirow{3}{*}{$\underset{\mathscr{D}}{\stackrel{\mathscr{D}}{\tilde{E}}}=$} & 29 & 0.616 & \multirow{3}{*}{0.559} \\
\hline & 14 & 0.503 & & & 32 & 0.528 & \\
\hline & 17 & 0.464 & & & 35 & 0.532 & \\
\hline \multirow{3}{*}{ 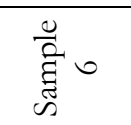 } & 12 & 0.673 & \multirow{3}{*}{0.604} & \multirow{3}{*}{ 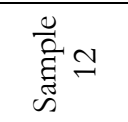 } & 30 & 0.720 & \multirow{3}{*}{0.745} \\
\hline & 15 & 0.580 & & & 33 & 0.740 & \\
\hline & 18 & 0.560 & & & 36 & 0.774 & \\
\hline
\end{tabular}

Table 10. ANOVA for HAp GRG

\begin{tabular}{|l|c|c|c|c|c|c|}
\hline \multicolumn{1}{|c|}{$\begin{array}{c}\text { Fabrication } \\
\text { parameter }\end{array}$} & DOF & Adj SS & Adj MS & F & $\begin{array}{c}\text { Contribution } \\
\mathbf{\%}\end{array}$ & Remark \\
\hline $\mathrm{Wt} \%$ of kaolin & 1 & 0.023324 & 0.023324 & 17.00 & 29.72 & Significant \\
\hline $\begin{array}{l}\text { Compaction } \\
\text { pressure }\end{array}$ & 1 & 0.006530 & 0.006530 & 4.76 & 8.32 & Significant \\
\hline $\begin{array}{l}\text { Sintering } \\
\text { temperature }\end{array}$ & 2 & 0.094503 & 0.047252 & 34.43 & 60.21 & Significant \\
\hline Residual error & 7 & 0.009607 & 0.001372 & & 1.75 & Insignificant \\
\hline Total & 11 & & 0.078478 & $\mathrm{~S}=0.03705$ & $\mathrm{R}^{2}=92.8 \%$ & $\mathrm{R}^{2}{ }_{\mathrm{Adj}}=88.7 \%$ \\
\hline
\end{tabular}

$$
\begin{gathered}
\gamma_{\text {predicted }}-C I<\gamma_{\text {experimental }}<\gamma_{\text {predicted }}+C I \\
0.5976<\gamma_{\text {experimental }}<0.7846
\end{gathered}
$$

The CI findings showed that the experimental GRG value of 0.6911 correlates with the predicted optimal GRG value. This affirms the efficacy of the optimal fabrication parameters on the multimechanical characteristics of kaolin reinforced hydroxyapatite.

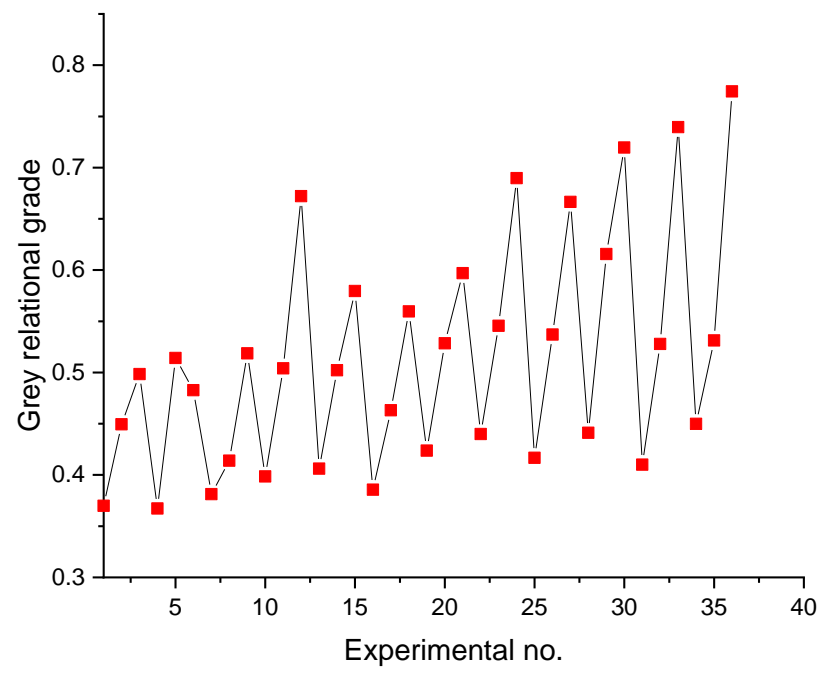

Figure 6. Grey relational grades 


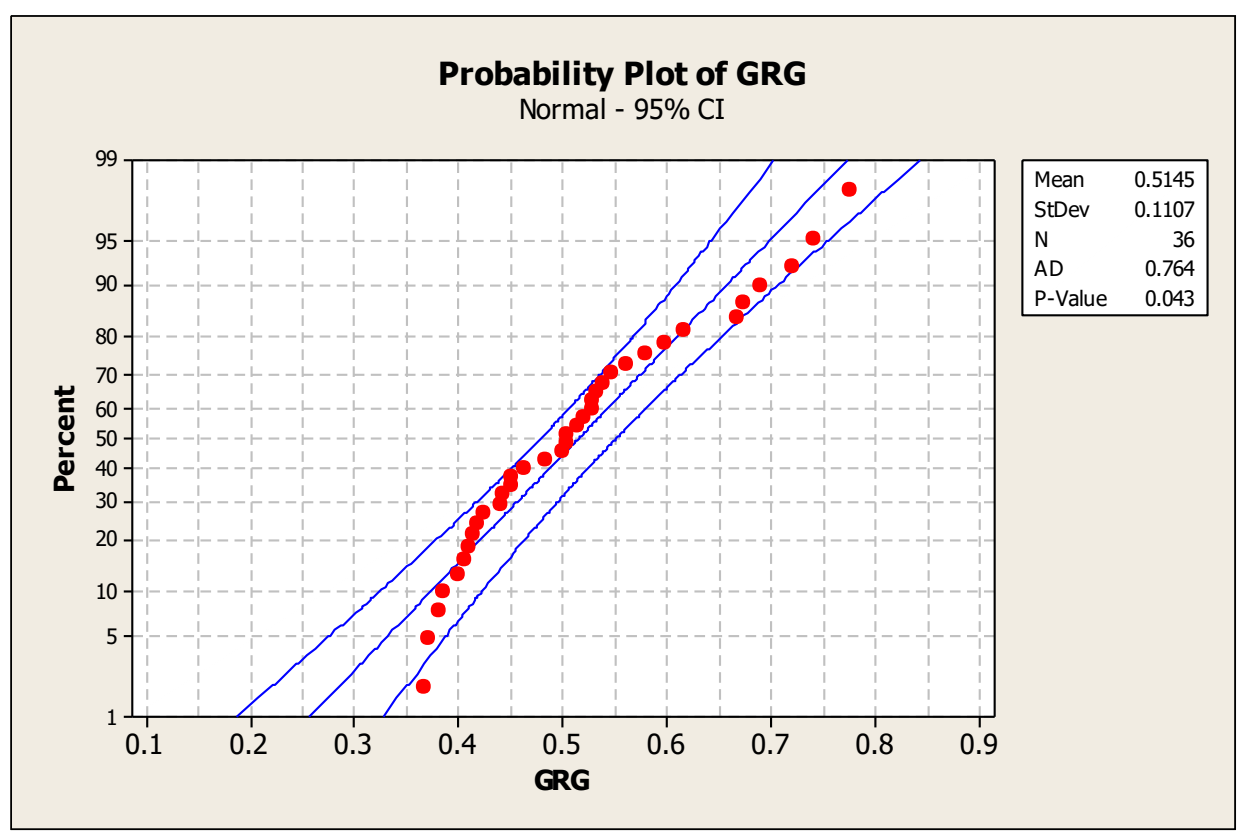

Figure 7. Probability plot of Grey Relational Grades

3.7.2 Probability distribution analysis: Figure 7 shows the probability plot and the statistical information of the multi-mechanical response of kaolin reinforced hydroxyapatite. The plot shows that all the GRG values except one are within the 95\% confidence interval, which is supported by the confirmation analysis.

\section{Conclusion}

The quantitative effect of kaolin reinforcement, compaction pressure and sintering temperature has been examined with the help of statistical analysis technique assisted by grey relational analysis. It was noted that there was disparity in kaolin reinforcement as the optimum condition for individual mechanical properties, showing better hardness but poorer compressive strength when HAp was not reinforced. However, the grey relational analysis showed better mechanical properties with kaolin reinforcement. $500 \mathrm{~Pa}$ compaction pressure and $1100^{\circ} \mathrm{C}$ sintering temperature are the optimum fabrication parameters for better mechanical properties, and was the same for individual mechanical properties. It is interesting to note that kaolin reinforcement significantly increased the compressive strength of HAp with a contribution of $93.16 \%$. This influenced GRG values, resulting to $15 \mathrm{wt} \%$ kaolin as the optimum with $500 \mathrm{~Pa}$ and $1100{ }^{\circ} \mathrm{C}$ sintering temperature as the optimal fabrication parameters for high strength of HAp. The confirmation analysis also revealed that the experimental multi-mechanical response is within the $95 \%$ confidence interval.

These findings are useful in orthopedics industry in order to produce a mechanically fitted HAp for load bearing clinical application. These findings recommend fabrication parameters at which mechanically improved clinical hydroxyapatite would be achieved. Further studies are also recommended conducted investigate the use of different $\mathrm{wt} \%$ of kaolin on the multiple mechanical characteristics of HAp.

\section{Acknowledgement}

The authors want to thank the Department of Mechanical Engineering and the Department of Metallurgical and Materials Engineering, Ahmadu Bello University, Zaria, for their support.

\section{References}

Abifarin, J. K. (2021). Taguchi grey relational analysis on the mechanical properties of natural hydroxyapatite: effect of sintering parameters. The International Journal of Advanced Manufacturing Technology, 117, 49-57. https://doi.org/10.1007/s00170-021-07288-9 
Abifarin, J. K., Obada, D. O., Dauda, E. T., \& Dodoo-Arhin, D. (2019). Experimental data on the characterization of hydroxyapatite synthesized from biowastes. Data in Brief, 26, 104485. https://doi.org/10.1016/j.dib.2019.104485

Abifarin, J. K., Suleiman, M. U., Abifarin, E. A., Fidelis, F. B., Oyelakin, O. K., Jacob, D. I., \& Abdulrahim, M. Y. (2021). Fabrication of Mechanically Enhanced Hydroxyapatite Scaffold With the Assistance of Numerical Analysis. Research Square. https://doi.org/10.21203/rs.3.rs-717243/v1

Adeogun, A. I., Ofudje, A. E., Idowu, M. A., \& Kareem, S. O. (2018). Facile Development of Nano Size Calcium Hydroxyapatite Based Ceramic from Eggshells: Synthesis and Characterization. Waste and Biomass Valorization, 9(8), 1469-1473. https://doi.org/10.1007/s12649-017-9891-3

Almetwally, A. A. (2020). Multi-objective Optimization of woven fabric parameters using Taguchi-Grey relational analysis. Journal of Natural Fibers, 17(10), 1468-1478. https://doi.org/10.1080/15440478.2019.1579156

Awodi, E., Ishiaku, U. S., Yakubu, M. K., \& Abifarin, J. K. (2021). Experimentally Predicted Optimum Processing Parameters Assisted by Numerical Analysis on the Multi-physicomechanical Characteristics of Coir Fiber Reinforced Recycled High Density Polyethylene Composites. Research Square. https://doi.org/10.21203/rs.3.rs-591200/v1

Bademlioglu, A. H., Canbolat, A. S., \& Kaynakli, O. (2020). Multi-objective optimization of parameters affecting Organic Rankine Cycle performance characteristics with Taguchi-Grey Relational Analysis. Renewable and Sustainable Energy Reviews, 117, 109483. https://doi.org/10.1016/j.rser.2019.109483

Bertazzo, S., Zambuzzi, W. F., Campos, D. D., Ogeda, T. L., Ferreira, C. V., \& Bertran, C. A. (2010). Hydroxyapatite surface solubility and effect on cell adhesion. Colloids and Surfaces B: Biointerfaces, 78(2), 177-184. https://doi.org/10.1016/j.colsurfb.2010.02.027

Byrne, D., \& Clore, G. L. (1970). A reinforcement model of evaluative responses. Personality: An International Journal, 1(2), 103-128. https://psycnet.apa.org/record/1972-08748-001

Caliman L. B., Silva S. N. and Junkes J. A. (2017). Ostrich Eggshell as an Alternative Source of Calcium Ions for Biomaterials Synthesis. Materials Research, 20(2), 413-417. https://doi.org/10.1590/1980-5373MR-2016-0368

Chang, S.-H., Hwang, J.-R., \& Doong, J.-L. (2000). Optimization of the injection molding process of short glass fiber reinforced polycarbonate composites using grey relational analysis. Journal of Materials Processing Technology, 97(1-3), 186-193. https://doi.org/10.1016/S0924-0136(99)00375-1

Chen, P. Y., Lin, M. L., \& Zheng, Z. (1997). On the origin of the name kaolin and the kaolin deposits of the Kauling and Dazhou areas, Kiangsi, China. Applied Clay Science, 12(1-2), 1-25. https://doi.org/10.1016/S0169-1317(97)00007-0

German, R. M. (2010). 1 - Thermodynamics of sintering. In Sintering of Advanced Materials (pp. 3-32). Woodhead Publishing. https://doi.org/10.1533/9781845699949.1.3

Javed, S. A. (2019). A novel research on grey incidence analysis models and its application in project management (doctoral dissertation). Nanjing University of Aeronautics and Astronautics, Nanjing, P.R. China.

Javed, S. A., Khan, A. M., Dong, W., Raza, A., \& Liu, S. (2019). Systems evaluation through new grey relational analysis approach: an application on thermal conductivity-petrophysical parameters' relationships. Processes, 7(6), 348. https://doi.org/10.3390/pr7060348

Julong, D. (1989). Introduction to grey system theory. The Journal of Grey System, 1(1), 1-24.

Kuang, X., Carotenuto, G., \& Nicolais, L. (1997). A review of ceramic sintering and suggestions on reducing sintering temperatures. Advanced Performance Materials, 4(3), 257-274. https://doi.org/10.1023/A:1008621020555

Lahiri, D., Ghosh, S., \& Agarwal, A. (2012). Carbon nanotube reinforced hydroxyapatite composite for orthopedic application: a review. Materials Science and Engineering: C, 32(7), 1727-1758. https://doi.org/10.1016/j.msec.2012.05.010

Mahmoudi, A., Javed, S. A., Liu, S., \& Deng, X. (2020). Distinguishing coefficient driven sensitivity analysis of GRA model for intelligent decisions: application in project management. Technological and Economic Development of Economy, 26(3), 621-641. https://doi.org/10.3846/tede.2020.11890

Murray, H. H. (1980). Major kaolin processing developments. International Journal of Mineral Processing, 7(3), 263-274. https://doi.org/10.1016/0301-7516(80)90022-8

Obada, D. O., Dauda, E. T., Abifarin, J. K., Bansod, N. D., \& Dodoo-Arhin, D. (2021). Mechanical measurements of pure and kaolin reinforced hydroxyapatite-derived scaffolds: A comparative study. Materials Today: Proceedings, 38, 2295-2300. https://doi.org/10.1016/j.matpr.2020.06.412

Obada, D. O., Dauda, E. T., Abifarin, J. K., Dodoo-Arhin, D., \& Bansod, N. D. (2020). Mechanical properties of natural hydroxyapatite using low cold compaction pressure: Effect of sintering 
$\begin{array}{lllll}\text { temperature. } \quad \text { Materials Chemistry and } & \text { Physics, }\end{array}$ https://doi.org/10.1016/j.matchemphys.2019.122099

Orlovskii, V. P., Komlev, V. S., \& Barinov, S. M. (2002). Hydroxyapatite and hydroxyapatite-based ceramics. Inorganic Materials, 38(10), 973-984. https://doi.org/10.1023/A:1020585800572

Posner, A. S., Perloff, A., \& Diorio, A. F. (1958). Refinement of the hydroxyapatite structure. Acta Crystallographica, 11(4), 308-309. https://doi.org/10.1107/S0365110X58000815

Ross, P. J. (1996). Taguchi Techniques for Quality Engineering: Loss Function, Orthogonal Experiments, Parameter and Tolerance Design. New York: McGraw-Hill Publishing Company Ltd.

Santos, J. D., Knowles, J. C., Reis, R. L., Monteiro, F. J., \& Hastings, G. W. (1994). Microstructural characterization of glass-reinforced hydroxyapatite composites. Biomaterials, 15(1), 5-10. https://doi.org/10.1016/0142-9612(94)90188-0

Schroeder, P. A., \& Erickson, G. (2014). Kaolin: From ancient porcelains to nanocomposites. Elements, 10(3), 177-182. https://doi.org/10.2113/gselements.10.3.177

Seward, J. P. (1956). Reinforcement and expectancy: two theories in search of a controversy. Psychological Review, 63(2), 105. https://doi.org/10.1037/h0045433

Singh, J., Chatha, S. S., \& Singh, H. (2021). Characterization and corrosion behavior of plasma sprayed calcium silicate reinforced hydroxyapatite composite coatings for medical implant applications. Ceramics International, 47(1), 782-792. https://doi.org/10.1016/j.ceramint.2020.08.189

Singh, S., Pandey, K. K., Islam, A., \& Keshri, A. K. (2020). Corrosion behaviour of plasma sprayed graphene nanoplatelets reinforced hydroxyapatite composite coatings in simulated body fluid. Ceramics International, 46(9), 13539-13548. https://doi.org/10.1016/j.ceramint.2020.02.139

Sylajakumari, P. A., Ramakrishnasamy, R., \& Palaniappan, G. (2018). Taguchi grey relational analysis for multi-response optimization of wear in co-continuous composite. Materials, 11(9), 1743. https://doi.org/10.3390/ma11091743

Taguchi, G. (1993). Taguchi on Robust Technology Development: Bringing Quality Engineering Upstream. New York: ASME Press.

Taguchi, G., \& Phadke, M. S. (1989). Quality engineering through design optimization. In Quality Control, Robust Design, and the Taguchi Method (pp. 77-96). Springer, Boston, MA. https://doi.org/10.1007/978-14684-1472-1_5

Taguchi, G., Chowdhury, S., Wu, Y., Taguchi, S., \& Yano, H. (2005). Taguchi's quality engineering handbook. Wiley-Interscience.

Zhao, X., Chen, X., Zhang, L., Liu, Q., Wang, Y., Zhang, W., \& Zheng, J. (2018). Preparation of nanohydroxyapatite coated carbon nanotube reinforced hydroxyapatite composites. Coatings, 8(10), 357. https://doi.org/10.3390/coatings8100357 